\title{
Inhibiting Effect of Swietenia Macrophylla Leaf Extract on Zinc Corrosion in Hydrochloric Acid Solution
}

\author{
Alfred I. Onen*, Onumashi A. Ushie, Christiana E. Attah \\ Department of Chemical Sciences, Federal University, Wukari, Taraba State, Nigeria
}

*Corresponding Author: Alfred I. Onen, Department of Chemical Sciences, Federal University, Wukari, Taraba State, Nigeria

\begin{abstract}
The inhibitory properties of Swietenia macrophylla (SM) leaf extract was tested on the corrosion of zinc in $0.5 \mathrm{M} \mathrm{HCl}$ solution using gravimetric and potentiodynamic polarization measurements. It was observed that the SM leaf extract acts as a good inhibitor for zinc at all concentrations. It was however found that, the inhibition efficiency (\% $I_{E}$ ) of SM increased with increase in concentration but decreased with increase in temperature. The mean value of activation energy, Ea for the inhibitor studied $\left(13.52 \mathrm{kJmol}^{-1}\right)$ is lower than $40.0 \mathrm{kJmol}^{-1}$ implying that the inhibitor is physically adsorbed on zinc surface. All the values of heat of adsorption $Q_{a d s}$ and mean values of free energy change of adsorption (-12.46 and -13.08kJmol ${ }^{-1}$ ) are negative indicating that the inhibition process is spontaneous and exothermic.
\end{abstract}

Keywords: Swietenia macrophylla, zinc, gravimetric technique, potentiodynamic polarization, physical adsorption

\section{INTRODUCTION}

Zinc is a very important metal used in a wide range of applications by various industries, e.g.as a construction material for roofs and facades in structural and civil engineering or as a sacrificial coating to protect iron and steel producing and processing industry, especially the automotive industry [1]. Zinc is a very active metal so that it corrodes quickly in aqueous solutions. The zinc coated steel materials provide a greater resistance to corrosion but when exposed to humid atmosphere, they undergo rapid corrosion with the formation of a corrosion product known as white rust[2].

The formation of white rust is generally observed in galvanized materials and renders the plated zinc materials unsuitable for industrial applications. Also, industrial processes such as scale removal and cleaning of zinc surfaces with acidic solutions expose zinc to corrosion. The beginning and spread of corrosion are major anxieties in various industries. As a result, corrosion inhibitors are frequently used to defend metals and alloys against corrosion.

However, due to the health and environmental concerns, there has been an increase in formulating new inhibitors that could be less harmful to the environment and human health but equally to achieve better corrosion protection. Therefore, green inhibitors have been extensively investigated for corrosion control in recent years. These green inhibitors are natural organic compounds and can be either manufactured or extracted from medicinal plants and herbs [3]. Organic inhibitors were applied extensively to protect metals from corrosion in many aggressive acidic media [4].

Organic compounds containing nitrogen, sulphur and oxygen atoms were found to be good corrosion inhibitors of metals particularly for active metals like iron, zinc and magnesium etc. The effectiveness of these compounds as corrosion inhibitors has been interpreted in terms of their molecular structure, molecular size, and molecular mass, hetero-atoms present and adsorptive tendencies. Under certain conditions, the electronic structure of the organic inhibitors has a key influence on the corrosion inhibition efficiency to the metal. Inhibitors influence the kinetics of the electrochemical reaction which constitute the corrosion process and thereby modify the metal dissolution in acids [4]. Latest trends in corrosion control seem to be shifting towards the use of plant extracts such as pistachio essential oils, ginger, lavender oil, limonene etc. This is due to their good combination of properties such as stability, price, ease of extraction, treatment, etc. Among the various plant extracts, those 
which contain atoms with high electronegativity are known to be having probably the best protection [3]. This work is aimed at determining the inhibitory properties of Swietenia macrophylla (Mahogany) leaf extract on zinc corrosion.

\section{MATERIALS AND METHODS}

\subsection{Material Preparation}

The zinc sheets used for this study were mechanically press-cut into $3 \times 4 \mathrm{~cm}$ coupons of $0.025 \mathrm{~cm}$ thickness. The coupons were examined carefully to check for rough edges, which could influence the corrosion monitoring process. Surface treatment of the coupons was done by degreasing in absolute ethanol and drying in acetone. They were then stored in moisture free desiccators before corrosion study commenced.

Fresh leaves of Swietenia macrophylla were dried to reduce the moisture content and ground into powder. $50 \mathrm{~g}$ of which was weighed into $100 \mathrm{~mL}$ of $90 \%$ ethanol in a $200 \mathrm{~mL}$ volumetric flask. The flask was properly corked and left to stand for 48 hours with occasional shaking. The resultant mixture was filtered and ethanol evaporated to dryness at $65^{\circ} \mathrm{C}$ in a water bath. This left a dark brown sticky residue, $10 \mathrm{~g}$ of which was weighed, dissolved in $100 \mathrm{~mL}$ of ethanol and made up to $1000 \mathrm{~mL}$ by $0.5 \mathrm{M} \mathrm{HCl}$ solution. This represents the stock solution from which different concentrations of 10 , $30,50,70$, and $100 \mathrm{mgdm}^{-3}$ wereprepared by dilution with the same acid solution of Swietenia macrophylla [5]. All the reagents are of analar grade.

\subsection{Weight Loss Measurements}

In the weight loss experiment, five $250 \mathrm{~mL}$ beakers (in two sets) were labeled $\mathrm{A}, \mathrm{B}, \mathrm{C}, \mathrm{D}$ and $\mathrm{E}$ containing $0.1,0.1,0.3,0.4$, and $0.5 \mathrm{M} \mathrm{HCl}$ solutions were placed in a water bath maintained at 303 Kand $313 \mathrm{~K}$. The zinc coupons were suspended in the beakers with the aid of glass hooks. The coupons were retrieved from their corrodent solutions at 24 hourly intervals for 7 days. Further measurements were carried out after introduction of the additives (Swietenia macrophylla) in the beakers maintained at $303 \mathrm{~K}$ and $313 \mathrm{~K}$. They were retrieved from the medium at 24 hours interval for 7 days. Each set of coupons were washed by scrubbing with a light brush and dried in propanone and finally in an oven maintained at $80^{\circ} \mathrm{C}$. The weight loss of zinc coupons was evaluated in grams as the difference in the weight of the coupons before and after the test [5].

$\mathrm{W}=\left(\mathrm{W}_{\mathrm{i}}-\mathrm{W}_{\mathrm{f}}\right) \mathrm{mg}$

$\mathrm{W}=$ weight loss of coupon, $\mathrm{Wi}=$ Initial weight of zinc coupon, $\mathrm{W}_{\mathrm{f}}=$ Final weight of zinc coupon.

The inhibition efficiency of Swietenia macrophylla extract acting as inhibitor was calculated using the formula,

$\% \mathrm{I}_{E}=\frac{\mathrm{W} 0-\mathrm{W} 1}{\mathrm{~W} 0} \times 100$

Where $\mathrm{w}_{\mathrm{o}}$ and $\mathrm{w}_{1}$ are the weight losses $(\mathrm{mg})$ for zinc in the presence and absence of additives respectively in $\mathrm{HCl}$ solution at the same temperature.

The degree of surface coverage, $\theta$ is given by the equation.

$\theta=\frac{\mathrm{W} 0-\mathrm{W} 1}{\mathrm{~W} 0}$

The corrosion rate $(\rho)$ of zinc in the different corrosion medium and Swietenia macrophylla was determined for a 168 hours immersion period from weight loss using the formula,

Corrosion Rate $(\mathrm{mdd})=\frac{\mathrm{W}}{\mathrm{DAT}}$

Where $\mathrm{w}=$ weight loss $(\mathrm{mg}) \mathrm{D}=$ density of specimen $\left(\mathrm{g} / \mathrm{cm}^{3}\right) \mathrm{A}=$ area of specimen $\left(\mathrm{cm}^{3}\right)$ and $\mathrm{T}=$ exposure time (hours).

\subsection{Electrochemical (Polarization) Measurements}

Electrochemical experiments were conducted in a conventional three-electrode cell voltammeter. Zinc specimens were used as a working electrode, platinum $(\mathrm{Pt})$ electrode and saturated calomel electrode (SCE) served as auxillary and reference electrodes, respectively. All electrochemical experiments were conducted at room temperature $\left(30 \pm 2{ }^{\circ} \mathrm{C}\right)$ using $100 \mathrm{~mL}$ of test solution. Before the potentio 
dynamic polarization, the working electrode was left to reach a stable open circuit potential (OCP) value of Ecorr. AC impedance measurements were carried out at the corrosion potential with frequency range of 10,000 to $0.1 \mathrm{~Hz}$ at an amplitude of $10 \mathrm{mV}$ and scan rate of 1 . The $\% \mathrm{I}_{\mathrm{E}}$ was calculated from the charge transfer resistance $\left(\mathrm{R}_{\mathrm{ct}}\right)$ values by using the equation

$\% I E=\frac{R_{c t}(1)-R_{c t}(0)}{R_{c t}(1)} \times 100$

where, $R_{\mathrm{ct}(0)}$ is the charge transfer resistance of zinc without inhibitor and $\mathbf{R}_{\mathrm{ct}(1)}$ is the charge transfer resistance of zinc with inhibitor.

Potentiodynamic polarization Tafel curves were obtained by automatically changing the electrode potential from -6000 to $-400 \mathrm{mV}$ at open circuit potential. Measurements were performed with Autolab model 302instrument, using a computer interface fitted with Nova version 1.9 software [6].

$\% I E=\frac{I_{\text {corr }(0)}-I_{\text {corr }(1)}}{I_{\text {corr }(0)}} \times 100$

where, $I_{\text {corr(0) }}$ is the corrosion current densities of zinc without inhibitor and $I_{\text {corr(1) }}$ is the corrosion current densities of zinc with inhibitor.

\section{RESULTS AND DISCUSSION}

\subsection{Effect of Corrodent Concentration and Temperature on Zinc Corrosion}

Corrosion rate (mdd) was observed to be higher at $313 \mathrm{~K}$ than $303 \mathrm{~K}$. A plot of weight loss of zinc specimen against time (Days) in $0.5 \mathrm{M} \mathrm{HCl}$ solution for 168 hours at $303 \mathrm{~K}$ and $313 \mathrm{~K}$ are shown in figure 1. A plot of weight loss against inhibitor concentration is shown in figure 2. A column chart showing inhibition efficiency $(\% \mathrm{I})$ against inhibitor (SM leaf extract) concentration in $0.5 \mathrm{M} \mathrm{HCl}$ solution for zinc at $303 \mathrm{~K}$ and $313 \mathrm{~K}$ is shown in figure 3.

From Table 1, and figure 2 , it is observed that inhibition efficiency $\left(\% \mathrm{I}_{\mathrm{E}}\right)$ and surface coverage $(\Theta)$ for zinc metal decrease with increase in temperature.

Figure 1 and table 1 show the variation of weight loss and corrosion rate with time (Days) for zinc in $0.5 \mathrm{M} \mathrm{HCl}$ at $303 \mathrm{~K}$ and $313 \mathrm{~K}$ with SM. It was observed that weight loss, corrosion rate (mdd) of zinc increased with increasing concentration in $\mathrm{HCl}$ solution. This could be attributed to the fact that rates of chemical reaction generally increase with increasing acid concentration and temperature. This assertion agrees with the findings of Abdallah et al; 2014 [7].

Table1. Corrosion Parameters for Zinc in 0.5M HCl containing SM Leaf Extract

\begin{tabular}{|c|c|c|c|c|c|c|c|c|}
\hline $\begin{array}{l}\text { Inhibitor } \\
\text { Conc. } \\
\left(\mathrm{mg} / \mathrm{dm}^{3}\right)\end{array}$ & \multicolumn{2}{|c|}{ Weight loss (mg) } & \multicolumn{2}{|c|}{$\begin{array}{ll}\text { Corrosion } & \text { Rate } \\
(\mathrm{mdd}) \times 10^{-3} & \\
303 \mathrm{~K} \quad 313 \mathrm{~K} & \\
\end{array}$} & \multicolumn{2}{|c|}{$\begin{array}{ll}\text { Inhibition } & \text { efficiency } \\
\left(\mathrm{I}_{\mathrm{E}} \%\right) & \\
303 \mathrm{~K} & 313 \mathrm{~K} \\
\end{array}$} & $\begin{array}{l}\text { Surface } \\
(\theta) \\
303 \mathrm{~K}\end{array}$ & $\begin{array}{l}\text { Coverage } \\
313 \mathrm{~K}\end{array}$ \\
\hline BLANK & 1.2077 & 1.2651 & 2.02 & 2.11 & & & & \\
\hline SM & & & & & & & & \\
\hline 10 & 0.8879 & 0.9879 & 1.48 & 1.65 & 65.96 & 62.13 & 0.66 & 0.62 \\
\hline 30 & 0.7571 & 0.9571 & 1.26 & 1.60 & 70.97 & 63.30 & 0.71 & 0.63 \\
\hline 50 & 0.6747 & 0.8747 & 1.13 & 1.46 & 74.13 & 66.46 & 0.74 & 0.66 \\
\hline 70 & 0.6406 & 0.7306 & 1.07 & 1.22 & 75.43 & 71.98 & 0.75 & 0.72 \\
\hline 100 & 0.5994 & 0.6794 & 1.00 & 1.13 & 77.02 & 73.95 & 0.77 & 0.74 \\
\hline
\end{tabular}

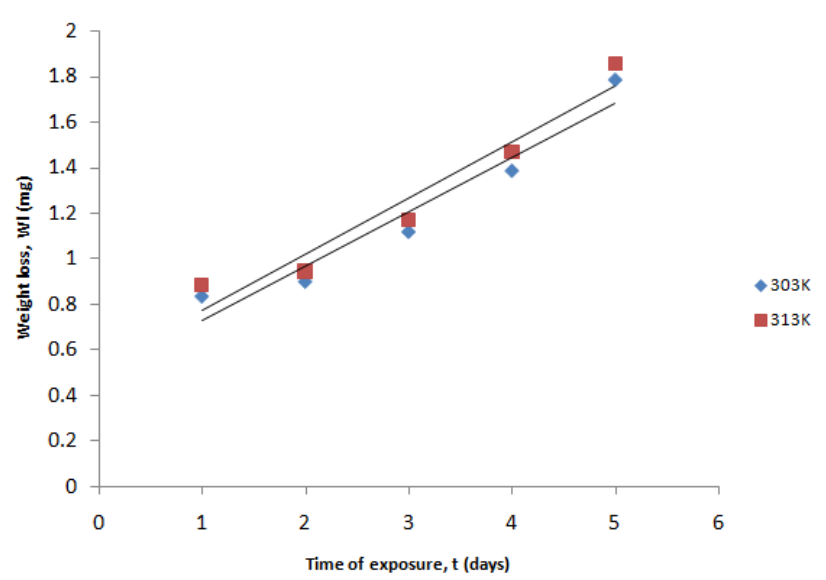

Fig1. Plot of Weight loss (mg) against exposure time (Days) for Zinc Corrosion in $0.5 \mathrm{M} \mathrm{HCl}$ 


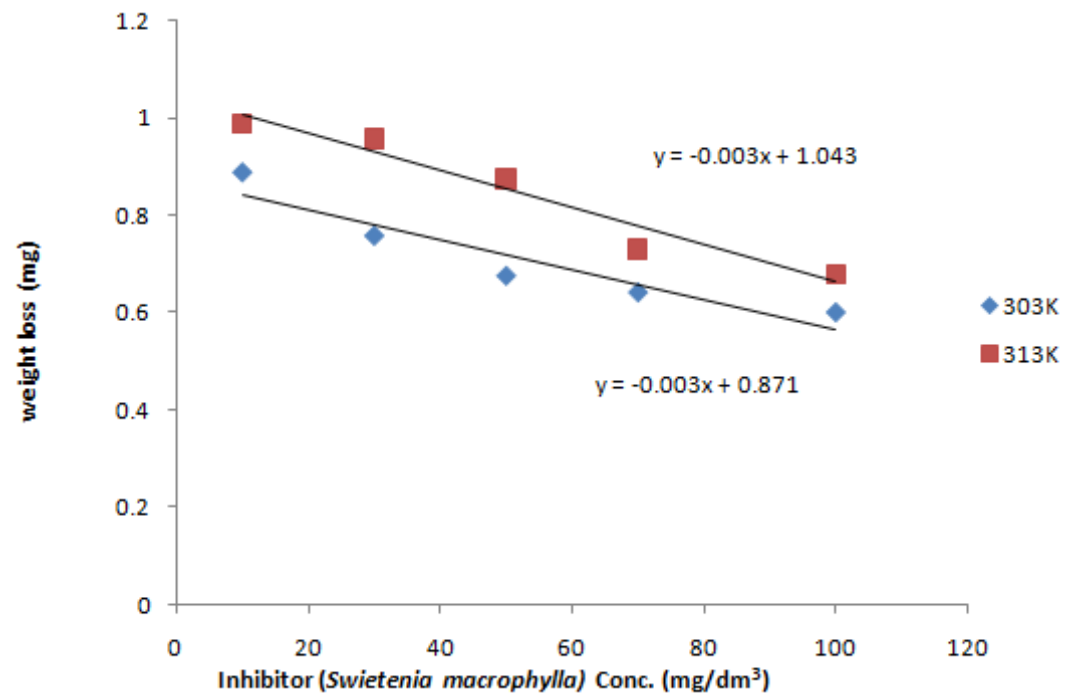

Fig2. Plot of Weight loss ( $m g$ ) of Zinc against Inhibitor (SM leaf extract) Concentration

\subsection{Effect of Inhibitor (SM) Concentration on Zinc Corrosion}

Figure 2 show variation of weight loss with inhibitors concentration for zinc corrosion in $0.5 \mathrm{M} \mathrm{HCl}$ with various concentrations of SM at $301 \mathrm{~K}$ and $313 \mathrm{~K}$. These graphs reveal that weight loss was lowest at $100 \mathrm{mg} / \mathrm{dm}^{3}$ (highest concentration of inhibitors studied). This indicates that SM inhibits corrosion of zinc to some extent, with inhibition increase with increasing inhibitor concentration at a lower temperature.

With the addition of the inhibitor $(\mathrm{SM})$ the inhibition efficiency $\left(\% \mathrm{I}_{\mathrm{E}}\right)$ (figure 3 ) and surface coverage were found to increase while corrosion rates decrease with increasing concentration in the order: $10 \mathrm{mg} / \mathrm{dm}^{3}<100 \mathrm{mg} / \mathrm{dm}^{3}, 303 \mathrm{~K}\left(65.69 \%\right.$ efficiency $<77.02 \%$ efficiency and $1.48 \times 10^{-3} \mathrm{mdd}>$ corrosion rate $1.00 \times 10^{-3}$ mdd corrosion rate) and $313 \mathrm{~K}(62.13 \%$ efficiency $<73.95 \%$ efficiency and $1.65 \times 10^{-3} \mathrm{mdd}$ corrosion rate $>1.13 \times 10^{-3} \mathrm{mdd}$ corrosion rate) but inhibition efficiency decrease with increasing temperature $(303 \mathrm{~K} \sim 313 \mathrm{~K})$ as in Table 1 . This shows that the inhibitors function effectively at lower temperature. This assertion agrees with findings of Ehteram, et al; 2016 [8].

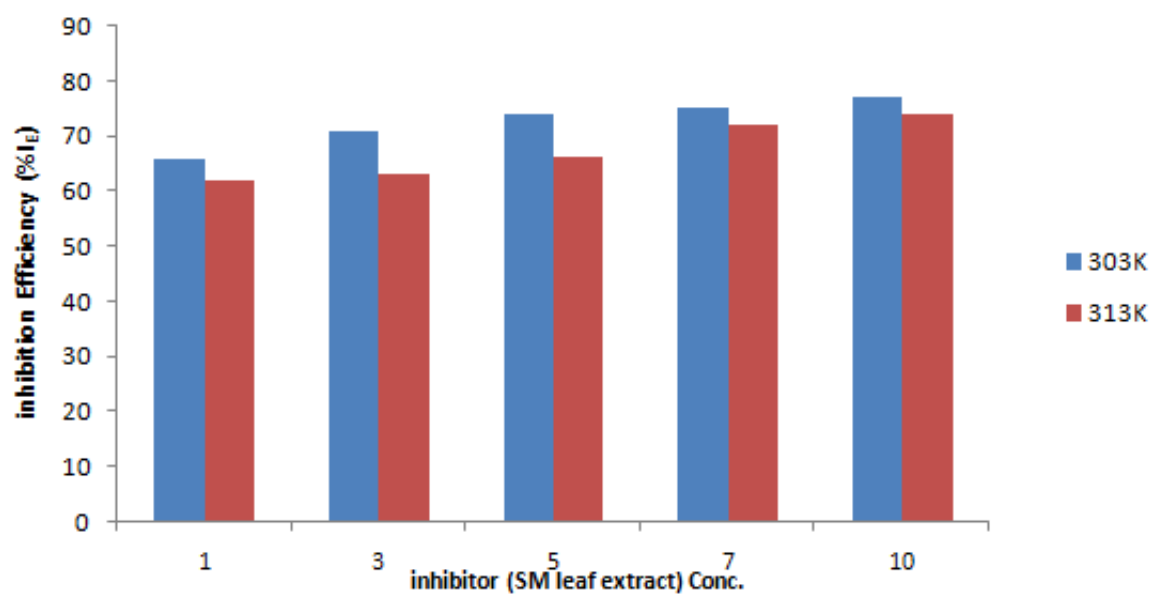

Fig3. Plot of inhibitor efficiency $\left(\% I_{E}\right.$ ) against inhibitor (SM leaf extract) concentration at $303 \mathrm{~K}$ and $313 \mathrm{~K}$

\subsection{Adsorption Parameters of the Inhibition Process}

From Table 1 and figure 3, it is evident that the inhibition efficiency $\left(\% \mathrm{I}_{\mathrm{E}}\right)$ and surface coverage $(\Theta)$ increase with increasing inhibitors concentration and decrease with increasing temperature. At high concentrations, lower surface coverage is observed because very little interaction between the adsorbed species would be expected. The surface coverage data implies that the adsorption of the inhibitor (SM) at the zinc interface may be due to electrostatic force between the adsorbates and the atoms on the metal surface. This assertion confirms to observation earlier published by Tareqet al; $2014[10]$. 
To establish the extent of adsorption of inhibitor on the zinc surface, some adsorption isotherm plots were made. The linear plots obtained from the graph of $\mathrm{C}_{\mathrm{eq}} / \Theta$ against $\mathrm{C}$ at $303 \mathrm{~K}$ and $313 \mathrm{~K}$ (figure 4 ), shows that the experimental data obtained within the temperature range fits Langmuir adsorption isotherm given by equation (7) below

$\mathrm{C}_{\mathrm{eq}} / \theta=\alpha " \mathrm{C}^{\prime \prime}+\beta$

Where $\mathrm{C}_{\mathrm{eq}}$ is the equilibrium concentration (Concentration at which no more weight loss was observed), $\mathrm{C}$ is the inhibitors concentration, $\theta$ is the surface coverage calculated from equation (4), $\alpha$ is the slope called the binding force and $\beta$ is the Langmuir constant which is the adsorptive capacity[7].

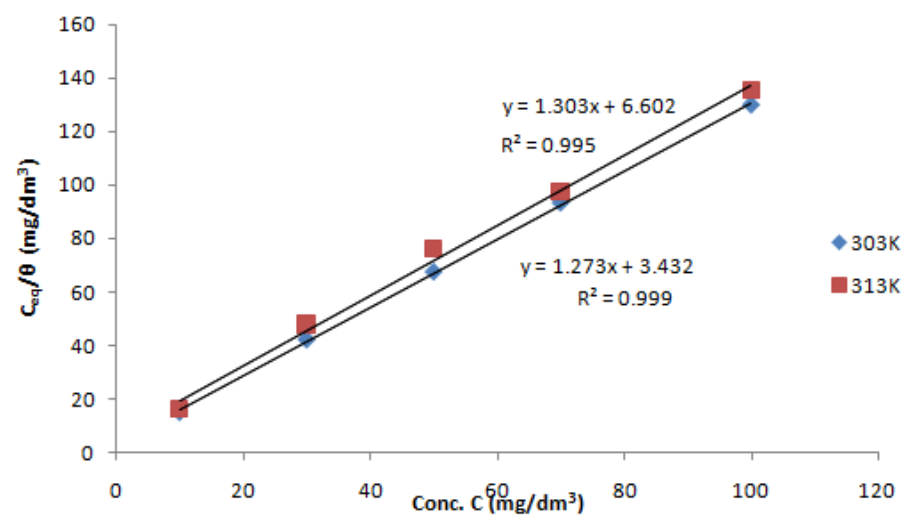

Fig4. Langmuir Isotherm Plotted as $C_{e q} / \Theta$ versus $C$ for zinc Corrosion in $0.5 \mathrm{M} \mathrm{HCl} \quad$ containing SM at $303 \mathrm{~K}$ and $313 \mathrm{~K}$

A plot of $\log \theta$ against $\log \mathrm{C}$ also shows that the adsorption of inhibitors on zinc surface in aqueous medium follows Freundlich isotherm. Therefore, the adsorption sites can be assumed to be distributed exponentially with respect to energy of adsorption and that the surface sites are subdivided into several types, each possessing a characteristic heat of adsorption [9]. Assumption of either Langmuir or Freundlich can therefore be used to determine the adsorption characteristics of the inhibitor.

The linear plot shown in Fig 5 signifies that the adsorption of the inhibitors on zinc surface in acid medium also follows Freundlich isotherm [7].

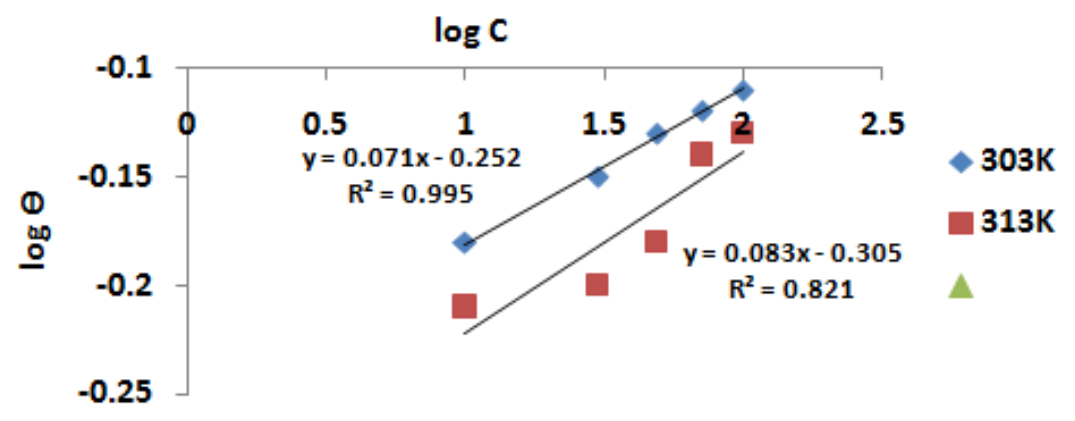

Fig5. Freundlich adsorption isotherm plotted as $\log \theta$ versus $\log C$

\subsection{Kinetic and Thermodynamic Parameters of Zinc Corrosion Inhibition}

The activation energy values in Table 2 were computed from the modified Arrhenius equation 8.

$\mathrm{Ea}=2.303 \mathrm{R} \frac{T 1 T 2}{T 2-T 1} \log \frac{\rho 2}{\rho 1}$

Where $\rho 1$ and $\rho 2$ are corrosion rates at $303 \mathrm{~K}$ and $313 \mathrm{~K}$ respectively. The values of rate constant $\mathrm{k}$ were obtained from plots of log mdd versus time (Day). The values of heat of adsorption $\mathrm{Q}_{\mathrm{mdd}}=19.147\left[\log \frac{\theta 2}{1-\theta 2}-\log \frac{\theta 1}{\theta 1}\right]\left[\frac{T 1 T 2}{T 2-T 1}\right]$

Where $\Theta_{1}$ and $\Theta_{2}$ are degree of surface coverage at $303 \mathrm{~K}$ and $313 \mathrm{~K}$ respectively [5]. The half - life values were obtained from the relation:

$\mathrm{t}_{1 / 2}=0.693 / \mathrm{k}$

All the values of $\mathrm{Q}_{\mathrm{mdd}}$ are negative for zinc corrosion as shown in Table 2. This implies that the 
inhibition process is spontaneous. It is also an indication that adsorption and inhibition efficiency decrease in temperature which agree with the findings of Tareq et al; 2014 [10].

Activation energy, Ea, values (Table 2) in the presence and absence of the inhibitor is

suggestive of formation of an adsorption film that is physical (electrostatic) nature. This is further enunciated by the fact that the mean activation energy value of $13.52 \mathrm{kJmol}^{-1}$ in an indication that the inhibitor is physically adsorbed on the metal coupons.

Half-life values increases and corrosion rates decrease with concentration confirming that there is more protection of the metal coupons by the $S M$ extracts.

Table2. Kinetic Data for Zinc Corrosion in $0.5 \mathrm{M} \mathrm{HCl}$ with Inhibitor (Swietenia macrophylla) at $303 \mathrm{~K}$ and $313 K$

\begin{tabular}{|c|c|c|c|c|c|c|}
\hline $\begin{array}{l}\text { Inhibitor Conc. } \\
\left(\mathrm{mg} / \mathrm{dm}^{3}\right)\end{array}$ & $\begin{array}{l}\text { Rate C } \\
\left(\mathrm{m}^{-1}\right)> \\
303 \mathrm{~K}\end{array}$ & $\begin{array}{l}\text { ant } \mathrm{K} \\
313 \mathrm{~K}\end{array}$ & $\begin{array}{l}\text { Half-li } \\
10 \\
303 \mathrm{~K}\end{array}$ & $\begin{array}{l}2(\mathrm{~min}) \times \\
313 \mathrm{~K}\end{array}$ & $\begin{array}{l}\text { Activation Energy } \\
\mathrm{Ea}\left(\mathrm{kJmol}^{-1}\right)\end{array}$ & $\begin{array}{l}\text { Heat of Adsorption } \\
\mathrm{Q}\left(\mathrm{kJmol}^{-1}\right) \times 10^{3}\end{array}$ \\
\hline BLANK & 6.58 & 6.92 & 1.05 & 1.00 & - & - \\
\hline \multicolumn{7}{|l|}{ SM } \\
\hline 10 & 1.67 & 1.51 & 4.15 & 4.59 & 8.58 & -13.70 \\
\hline 30 & 2.56 & 2.00 & 2.71 & 3.47 & 18.84 & -28.64 \\
\hline 50 & 2.96 & 2.27 & 2.34 & 3.05 & 20.21 & -30.18 \\
\hline 70 & 3.16 & 2.77 & 2.19 & 2.50 & 10.35 & -12.16 \\
\hline 100 & 4.41 & 3.89 & 1.57 & 1.78 & 9.64 & -12.80 \\
\hline Mean & & & & & 13.52 & -19.50 \\
\hline
\end{tabular}

Free energy change of adsorption, $\Delta G_{\text {ads }}$ of the corrosion process (reflected in Tables 3 and 4), may be determined from data obtained from Langmuir and Freundlich plots using the equation:

$\Delta \mathrm{G}_{\mathrm{ads}}=-2.303 \mathrm{RT} \log \left(55.5 \mathrm{~K}_{\mathrm{ads}}\right)$

where $\mathrm{R}$ is the molar gas constant, $\mathrm{T}$ is absolute temperature and $\mathrm{K}_{\mathrm{ads}}$ is the equilibrium constant of adsorption[11].

Table3. Thermodynamic Parameters calculated from Langmuir adsorption Isotherm at $303 \mathrm{~K}$ and $313 \mathrm{~K}$

\begin{tabular}{|c|c|c|c|c|c|c|}
\hline Inhibitor & Temperature (K) & Intercept & Slope & $\mathbf{K}_{\text {ads }}\left(\mathbf{M}^{-1}\right)$ & $\mathbf{r}^{2}$ & $\Delta \mathbf{G}_{\text {ads }}(\mathbf{k J} / \mathbf{m o l})$ \\
\hline SM & $303 \mathrm{~K}$ & 8.345 & 1.3033 & 1.968 & 0.9996 & -11.83 \\
\hline & $313 \mathrm{~K}$ & 10.100 & 1.2731 & 2.752 & 0.9957 & -13.09 \\
\hline Mean & & & & & & $\mathbf{- 1 2 . 4 6}$ \\
\hline & & & & & & \\
\hline
\end{tabular}

Table4. Thermodynamic Parameters calculated from Freundlich adsorption Isotherm at $303 \mathrm{~K}$ and $313 \mathrm{~K}$

\begin{tabular}{|c|c|c|c|c|c|c|}
\hline Inhibitor & Temperature (K) & Intercept & Slope & $\mathbf{K}_{\text {ads }}$ & $\mathbf{r}^{2}$ & $\Delta \mathbf{G}_{\text {ads }}(\mathbf{k J} / \mathbf{m o l})$ \\
\hline SM & 303 & 2.113 & 0.0712 & 2.782 & 0.9952 & -12.70 \\
\hline & 313 & 2.335 & 0.0831 & 3.156 & 0.8214 & -13.45 \\
\hline Mean & & & & & & $\mathbf{- 1 3 . 0 8}$ \\
\hline
\end{tabular}

The mean values of $\Delta \mathrm{G}_{\text {ads }}$ were found to be $-12.46 \mathrm{kJmol}^{-1}$ and $-13.08 \mathrm{kJmol}^{-1}$ from Langmuir and Freundlich isotherms. This is used to characterize the adsorption of the inhibitor molecules on the metal surface. The negative values of $\Delta \mathrm{G}_{\mathrm{ads}}$ signify the spontaneity of adsorption the process and stability of the adsorbed layer on the zinc surface. If the mean values of $\Delta \mathrm{G}_{\mathrm{ads}}$ are $-20 \mathrm{kJmol}^{-1}$ or less, then the inhibition process is in conformity with physisorption mechanism and if the mean $\Delta \mathrm{G}_{\text {ads }}$ values are $-40 \mathrm{kJmol}^{-1}$ or higher, then chemisorption is proposed. This assertion is in agreement with earlier findings of Ehteram et al., 2016 [8].As shown in Tables 3 and $4, \Delta \mathrm{G}_{\text {ads }}$ values obtained are all negative less than $-20 \mathrm{kJmol}^{-1}$. Hence, physical adsorption is authenticated in this case. This agrees with our earlier report [12]. This means that the plant extract adheres on the surface of the metal and so enhances the stability of the inhibitor which is a characteristic of a strong inhibitor.

\subsection{Analysis of Electrochemical (Polarization) Results}

The potentiodynamic polarization curves of zinc in $0.5 \mathrm{M} \mathrm{HCl}$ solution in the absence and presence Swietneniamacrophylla, SM (Figure 6).Electrochemical parameters such as corrosion potential (Ecorr), corrosion current density (icorr), cathodic Tafel slope (bc) and inhibition efficiency $\eta p$ were calculated and shown in Table 5. The $\eta_{p}$ was calculated from polarization measurements according to 
the equation (6) above. Corrosion currents were obtained by the extrapolation of the current potential lines to the corresponding corrosion potentials $[6,14]$

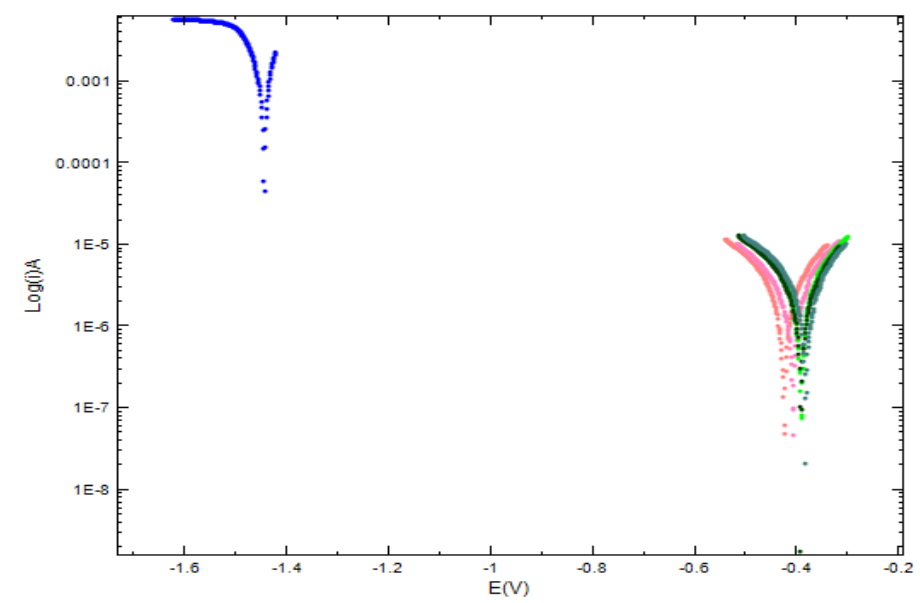

Figure6. Potentio dynamic linear polarization curves for zinc in $0.5 \mathrm{M} \mathrm{HCl}$ without and with different concentrations of SM at 303 and $313 \mathrm{~K}$ (immersion time 2 minutes)

It can clearly be seen from the polarization curves that, both anodic and cathodic curves were shifted toward the direction of lower current density for both inhibitors as the concentration increased when compared to the blank. This phenomenon indicates that the inhibitor can retard the anodic reaction of zinc dissolution and cathodic hydrogen evolutions, with cathodic reactions being predominant. Thus, this reveals that SM acts as a mixed-type inhibitor [13].

Table5. Electrochemical Polarisation parameters for zinc in $0.50 \mathrm{M} \mathrm{HCl}$ in the presence and absence of Swietenia macrophyllaat $303 \mathrm{~K}$

\begin{tabular}{|c|c|c|c|c|c|c|}
\hline System & $\begin{array}{l}\text { Conc. } \\
\left(\mathrm{mgL}^{-1}\right)\end{array}$ & $\begin{array}{l}-\mathrm{E}_{\text {corr }} \\
\left(\text { vsKCIEV }^{-1}\right)\end{array}$ & $\begin{array}{l}\mathbf{I}_{\text {corr }} \\
\left(\mathbf{1 0}^{-8} \mathbf{J A c m}^{2}\right)\end{array}$ & $\begin{array}{l}-\beta_{\mathrm{c}} \\
\left(\mathrm{mVdec}^{-1}\right)\end{array}$ & $\begin{array}{l}\beta_{\mathrm{a}} \\
(\mathrm{mVdec} \\
-1)\end{array}$ & $\begin{array}{l}\eta_{\mathrm{p}} \\
(\%)\end{array}$ \\
\hline Blank & 0.0 & 0.520 & 16.00 & 0.637 & 0.518 & - \\
\hline \multirow[t]{5}{*}{$S M$} & 10 & 0.561 & 3.962 & 0.635 & 0.548 & 71.02 \\
\hline & 30 & 0.511 & 2.747 & 0.616 & 0.508 & 83.95 \\
\hline & 50 & 0.470 & 1.784 & 0.567 & 0.467 & 89.50 \\
\hline & 70 & 0.380 & 0.857 & 0.502 & 0.388 & 94.90 \\
\hline & 100 & 0.413 & 0.606 & 0.511 & 0.401 & 96.40 \\
\hline
\end{tabular}

The efficiency values increased progressively with concentration to $96.40 \%$ (at the highest concentration of $100 \mathrm{mgdm}^{-3}$ studied). This increasing trend of inhibition efficiencies is consistent with those obtained from weight loss measurements. This agrees with the findings of Kumar et al., 2010 [15] and [16].

\section{CONCLUSION}

The following conclusions are drawn from the findings of the study:

$S M$ extractacted as good and efficient inhibitor for the corrosion of zinc in acid medium. Adsorption of the plant extract fitted into Langmuir and Freundlich adsorption isotherms. SM extractacted as a mixed inhibitor. The values of activation energy $\left(\mathrm{E}_{\mathrm{a}}\right)$ in the corrosion of zinc in $0.5 \mathrm{M} \mathrm{HCl}$ in the presence of extract was found to be higher than that corrodent indicating that the inhibitor provided a physical barrier to change and mass transfer, thus leading to reduction in rate of corrosion. The negative values of the free energy of adsorption, $\Delta \mathrm{G}_{\text {ads }}$ indicate that the adsorption of the inhibitors on the surface of the zinc was a spontaneous and was found to be physisorption. It further implies that the inhibition process is exothermic.

\section{REFERENCES}

[1] Abdallah M., El-Defrawy A. M., Zaafany I. A., Sobhi M., Elwahy A. H. M., and Shaaban M. R. (2014). Inhibition Effects and Theoretical Studies of Synthesized Nollel Bisaminothiazol Derivatives as Corrosion Inhibitors for Carbon Steel in Sulphuric acid solution. International Journal of Electrochemical Science.9.(2186-2207)

[2] Odoemelam, S., Ogoko, E., Ita B. \& Eddy N. (2009). "Adsorption and Inhibitive Properties of Clarithromycin for the Corrosion of $\mathrm{Zn}$ in 0.01 to $0.05 \mathrm{M} \mathrm{H}_{2} \mathrm{SO}_{4}$ ", Electrochim. Acta, 27,713-724. 
[3] Ismat H A (2016)Inhibitory Effect of Leaf Extract of Khayasenegalensis (Mahogany) on C-steel Corrosion in 1.0 M Hydrochloric Acid Solution International Journal of electrochemical science, 11: $2130-2141$

[4] Ashish K. S., Adilya K. S. and Ebenso, E. E. (2014). Inhibition Effect of Cefradine on Corrosion of Mild Steel in $\mathrm{HCl}$ Solution. International Journal of Electrochemical Science 9(352-364).

[5] Onen A. I., maltera O. N., Josheph J., and Ebenso E. E. (2011). Corrosion Inhibition Potential and Adsorption Behaviour of Bromophenol Blue and Thymol Blue Dyes on Mild Steel in Acidic Medium International Journal of Electrochemical Science. 8 2884-2897.

[6] Hammouti,B., Patel,N. S., Jauhariand,S., Mehta,G.N., Al-Deyab, S. S. and Warad, I.(2013).Mild Steel Corrosion Inhibition by various Plants Extracts in $0.5 \mathrm{M}$ Sulphuricacid. International Journal of Electrochemical Science, 2635-2655

[7] Abdallah M., Hazazi A., ALJahdaly B. A., Fouda A. S., El-Nagar W. (2014) Corrosion Inhibition of Zinc in Sodium Hydroxide Solutions using Coumarin Derivatives International Journal of Innovative Research in Science, Engineering and Technology 3, (2130 - 2141)

[8] Ehteram A. N, Aisha A., Aqlah H. A. and Manal H. H (2016) Testing and Comparing the Inhibitory Action of Red Onion Seeds and Peels Extract on the Corrosion of Steel in Phosphoric Acid International Journal of Electrochemical Science, 11(6523-6539).

[9] Fu J, Li S, Cao L, Wang Y, Yan L (2010). Journal of Material Science.45:979. doi:10.1007/ s10853-0094028-0ha

[10] Tareq T. Bataineh Mahmoud A. Al-Qudah Eyad M. Nawafleh Nathir A.F. and Al Rawashdeh (2014) Sinapis Alba Extract as Green Corrosion Inhibitor for Aluminum in Alkaline Media. International Journal of electrochemical science 9 (3543 - 3557).

[11] Obot IB, Obi-Egbedi NO, Umoren SA and Ebenso EE (2010).Synergistic and antagonistic effects of anions and Ipomoea invulcrataas green corrosion inhibitor for aluminium dissolution in acidic medium. Int. J. Electrochem. Science. 5(7):994-1007.

[12] Onen A I and Yakubu D U (2016), Chemical and Electrochemical Investigations of SpiderWisp / Cat's Whiskers (Cloeme Gynandra) as Corrosion Inhibitor for Mild Steel in Hydrochloric Acid Medium, InterJ Adv Res Chem Sci.3 (10), 27-35.

[13] Elyn A W, Rahim AA, Awang K and Raja P B (2011) Evaluation of the inhibitive effect of some extracts on the acid corrosion of mild steel, Corrosion Science 8-11.

[14] Hussin, M.H. and Kassim, M.J. (2010). Electrochemical studies of mild steel corrosion inhibition in aqueous solution by Uncariagambir extract. Journal of Physical Science, 21(1), 1 -13

[15] Kumar, K.P., Pillai, M.S.N. \& Thusnavis, G.R. (2010). Pericarp of the fruit of Garcunia mangostana as Corrosion inhibitor for mild steel in hydrochloric acid medium. Portugaliae Electrochimica Acta, 28 (6), $373-383$.

[16] Rani, D.P. and Selvaraj, S. (2010). Inhibitive and adsorptive properties of Punicagranatum extract on brass in acid media. Journal of Phytology, 2 (11), 58 - 64.

Citation: A. Onen, "Inhibiting Effect of Swietenia Macrophylla Leaf Extract on Zinc Corrosion in Hydrochloric Acid Solution", International Journal of Advanced Research in Chemical Science (IJARCS), vol. 4, no. 5, p. 1-8, 2017. http://dx.doi.org/10.20431/2349-0403.0405001

Copyright: (C) 2017 Authors. This is an open-access article distributed under the terms of the Creative Commons Attribution License, which permits unrestricted use, distribution, and reproduction in any medium, provided the original author and source are credited. 